\title{
The role of peritoneal biopsy in the diagnosis of ascites
}

\author{
P. F. JENKINS \\ M.R.C.P.
}

\author{
M. J. WARD \\ M.R.C.P.
}

The City Hospital, Nottingham NG5 IPB

\begin{abstract}
Summary
Percutaneous biopsies of the peritoneum were obtained in 23 patients with ascites of unknown cause. The only case of tuberculous peritonitis was correctly diagnosed. Peritoneal biopsy provided a diagnosis of malignancy in 6 patients (one lymphoma, one mesothelioma, 4 cases of disseminated carcinoma) but failed to recognize a further 13 cases of disseminated carcinoma. Previous literature is reviewed and the diagnostic usefulness of this procedure is discussed.
\end{abstract}

\section{Introduction}

The cause of ascites may be difficult to ascertain and recourse to invasive procedures, even laparotomy, may be necessary. Direct examination of ascitic fluid often fails to provide the diagnosis but previous reports have suggested that percutaneous biopsy is a more rewarding investigation.

In the first report of this procedure a modified Vim-Silverman needle was employed (Donohoe, Schnider and Gorman, 1959) and a correct histological diagnosis was achieved in 7 of the 14 patients studied. Subsequent investigators have used the side-biting Abrams and Cope needles (Cope and Bernhardt, 1963; Trujillo and Donohoe, 1965). Levine (1967) performed percutaneous peritoneal biopsies on 36 patients and tuberculosis was diagnosed in 20 of these with no false negative results. Malignancy was discovered on biopsy in 4 patients out of 8 with carcinoma. However, Levine was particularly interested in febrile, tuberculinpositive patients and his series therefore contains a disproportionate number of cases of tuberculous peritonitis.

The procedure of percutaneous peritoneal biopsy has gained acceptance in the United States of America and in India (Jain, Misra and Misra, 1964; Mehotra, Mathur and Wahi, 1964; Sarin, Mehta and Sharma, 1964; Virunavatti et al., 1966) but the present authors have found no report of its use in the United Kingdom. The present study investigated its diagnostic usefulness in patients presenting with undiagnosed ascites in a District General Hospital.

\section{Patients and methods}

Percutaneous peritoneal biopsy was performed in 23 patients in whom tuberculous or carcinomatous ascites was suspected. Informed consent was obtained and platelet count and prothrombin timeg were checked in each case before the procedure. This was performed at the bedside, under local $N$ anaesthetic and with conventional aseptic technique.응 An Abram's pleural biopsy needle was introduced. through a $0 \cdot 5-\mathrm{cm}$ skin incision in the right or lefto iliac fossa. Ascitic fluid was aspirated and submitted? to cytological, biochemical and bacteriological exam-ination. Biopsies of peritoneum were obtained by $\mathrm{a}^{-}$ technique similar to that used in obtaining pleufico biopsies. Difficulties arose, however, owing to there. being no rigid thoracic frame on which to purchase the mouth of the biopsy needle. This was overcome by inserting the needle, drawing back fluid and then withdrawing the needle with pressure from the skin surface with the free hand. This method wedged $\stackrel{\varnothing}{\varrho}$ the peritoneal surface into the biting biopsy needle.

The procedure proved easy and safe to perform. Bleeding was not encountered and leakage of ascites from the biopsy site was avoided by carefulo skin suturing.

\section{Results}

Twelve of the 23 patients were male. The average age was 64 years (range 29-80). The characteristics of ascitic fluid, the result of peritoneal biopsy ando the final diagnosis in each case are all summarized in Table 1 .

In general, direct examination of ascitic fluid was found to be unhelpful in deciding the cause of ascites. It suggested the diagnosis of carcinoma in N only 2 patients. Repeated examination of ascitic N్ల్ fluid from the patient with tuberculous peritonitis $\sigma$ failed to identify acid alcohol-fast bacilli. In contrast however, peritoneal biopsy was diagnostic in 8 of the 23 cases. The technique obtained peritoneum on all occasions. Biopsy was diagnostic in 4 patients 0 out of 16 with carcinoma. The single cases of tuberculous peritonitis, non-Hodgkin's lymphoma 
TABLE 1. Peritoneal biopsy results and cell content of ascitic fluid related to final diagnosis

\begin{tabular}{|c|c|c|c|}
\hline $\begin{array}{c}\text { No. of } \\
\text { patients } \\
(\text { Total=23) }\end{array}$ & Final diagnosis & Peritoneal biopsy & Cell content of ascitic fluid \\
\hline 4 & Carcinoma of pancreas & Normal peritoneum & A few lymphocytes \\
\hline 2 & Carcinoma of stomach & Adenocarcinoma & Lymphocytes \\
\hline 1 & Carcinoma of stomach & Fibrous thickening of peritoneum & Lymphocytes \\
\hline 1 & Hepatoma & Normal peritoneum & None \\
\hline 4 & Carcinoma of colon or rectum & Normal peritoneum & No cells or a few lymphocytes \\
\hline 3 & Carcinoma of ovary & $\begin{array}{l}\text { Normal peritoneum (1) or } \\
\text { fibrous thickening (2) }\end{array}$ & A few lymphocytes \\
\hline 1 & Carcinoma of ovary & Carcinoma cells & None \\
\hline 1 & Carcinoma of ovary & Normal peritoneum & Large number of atypical cells \\
\hline 1 & Mesothelioma & Mesothelioma & None \\
\hline 1 & Non-Hodgkin's lymphoma & $\begin{array}{l}\text { Peritoneal infiltrate with } \\
\text { lymphoma }\end{array}$ & Large numbers of lymphocytes \\
\hline 1 & Tuberculous peritonitis & $\begin{array}{l}\text { Caseating granulomata with } \\
\text { AAFB }\end{array}$ & Lymphocytes, no AAFB \\
\hline 1 & $\begin{array}{l}\text { Primary peritonitis underlying } \\
\text { liver disease }\end{array}$ & Acute peritonitis & Polymorphs anaerobic bacteria \\
\hline 1 & Cirrhosis & Normal peritoneum & None \\
\hline 1 & Unknown. Post-mortem refused & Carcinoma cells & Atypical cells seen \\
\hline
\end{tabular}

$\mathrm{AAFB}=$ acid alcohol-fast bacilli.

and mesothelioma were each correctly diagnosed by peritoneal biopsy.

\section{Discussion}

The results confirm that percutaneous peritoneal biopsy is both easy and safe to perform. Previous studies have emphasized the ability of peritoneal biopsy to diagnose tuberculous peritonitis (Donohoe et al., 1959; Trujillo and Donohoe, 1965). This is of particular importance, as early bacteriological confirmation of this disease is usually not possible and diagnosis has often to be established by surgical exploration or laparoscopy (Gonnella and Hudson, 1966). The single case of tuberculous peritonitis in the present series was readily diagnosed on biopsy despite repeated failure to find acid alcohol-fast bacilli on direct examination of ascitic fluid.

One case of lymphoma and one of mesothelioma were correctly diagnosed by peritoneal biopsy and, in each of these patients, further investigations as to the nature of their ascites were unnecessary. This finding was of particular importance in the case of mesothelioma in which further investigation such as laparotomy is particularly contra-indicated.

The $25 \%$ pick-up rate of carcinomatous ascites was disappointing but was more useful than examination of ascitic fluid alone.

The technique of percutaneous peritoneal biopsy is useful in the diagnosis of ascites. It may be the investigation of choice in tuberculous peritonitis as, indeed, pleural biopsy is in the diagnosis of tuberculous pleural effusion (Hirsch et al., 1979). In view of its relative ease and safety, peritoneal biopsy should be used routinely at the time of diagnostic paracentesis in all patients suspected of having malignant or tuberculous ascites before other more unpleasant and potentially hazardous procedures are performed.

\section{Acknowledgments}

We should like to thank the Consultant Staff at the City Hospital, Nottingham, for permission to investigate patients under their care, and for their encouragement with this paper.

\section{References}

Cope, D. \& Bernhardt, H. (1963) Hook-needle biopsy of pleura, pericardium, peritoneum and synovium. American Journal of Medicine, 35, 189.

Donohoe, R.F., SCHNider, B.I. \& Gorman, J. (1959) Needle biopsy of the peritoneum. Archives of Internal Medicine, 103, 739.

GoNnElla, J.S. \& Hudson, E.K. (1966) Clinical patterns of tuberculous peritonitis. Archives of Internal Medicine, $117,164$.

Hirsch, A., Ruffie, P., Nebut, M., Bignon, J. \& Chretien, J. (1979) Pleural effusion: laboratory tests in 300 cases. Thorax, 34, 106.

JAIN, S.C., MisRa, S.M. \& MisRa, N.P. (1964) Peritoneal biopsy in ascites. Journal of the Indian Medical Association, 43, 219.

LEVINE, H. (1967) Needle biopsy of peritoneum in exudative ascites. Archives of Internal Medicine, 120, 545.

Mehotra, M.P., Mathur, K.S. \& WAhi, P.N. (1964) Percutaneous biopsy of peritoneum as a diagnostic aid in cases of ascites. Journal of the Indian Medical Association, 43, 319.

Sarin, L.R., Mehta, S.R. \& Sharma, S.K. (1964) Diagnosis of abdominal tuberculosis: a critical evaluation of various techniques with particular reference to peritoneal biopsy. Indian Journal of Medical Sciences, 18, 319.

Trujillo, N.P. \& DonohoE, R.F. (1965) Needle biopsy of the peritoneum. American Journal of Medical Sciences, 249, 186.

Viranuvatti, V., Hitanant, S., Boonyapaknavig, V., Plenquanit, V., Kalayasiri, C. \& Chearani, O. (1966) Peritoneal biopsy: experience with blind and direct vision biopsy. American Journal of Proctology, 17, 488. 